\title{
JMJD2C triggers the growth of multiple myeloma cells via activation of $\beta$-catenin
}

\author{
MING LV ${ }^{1}$ and QICAI LIU ${ }^{2}$ \\ Departments of ${ }^{1}$ Emergency Medicine and ${ }^{2}$ Joint Surgery, \\ Zaozhuang Municipal Hospital, Zaozhuang, Shandong 277101, P.R. China
}

Received May 25, 2020; Accepted December 2, 2020

DOI: 10.3892/or.2021.7934

\begin{abstract}
Emerging evidence has indicated that histone modification and its related regulators are involved in the progression of multiple myeloma (MM) cells. In the present study, the expression of Jumonji C domain-containing 2 (JMJD2) was examined in both MM tissues and healthy controls. The roles of JMJD2C in the progression of MM were further investigated. The results revealed that the expression of JMJD2C, but not that of JMJD2A or JMJD2B, was increased in MM tissues compared with the healthy controls. The overexpression of JMJD2C significantly increased the in vitro growth of MM cells. The inhibitor of the $\beta$-catenin signaling pathway significantly attenuated the JMJD2C-induced growth of MM cells. Mechanistical analyses indicated that JMJD2C increased the transcription of $\beta$-catenin in MM cells, which may be due to the fact that JMJD2C can directly bind with the promoter of $\beta$-catenin. Furthermore, JMJD2C activated $\beta$-catenin in MM cells via a GSK3 $\beta$-dependent manner, which was evidenced by the results demonstrating that the overexpression of GSK3 $\beta$ attenuated the JMJD2C-induced decrease in the phosphorylation of $\beta$-catenin. On the whole, the findings of the present study demonstrated that JMJD2C promotes the malignancy of MM via the activation of the $\beta$-catenin pathway. These results suggested that JMJD2C may be a potential target for MM treatment.
\end{abstract}

\section{Introduction}

Multiple myeloma (MM) accounts for 10\% of all hematological malignancies $(1,2)$. As a complex plasmacell neoplasm, patients with MM exhibit highly heterogenous molecular characteristics $(3,4)$. Chemotherapy, targeted therapy, immunotherapy and hematopoietic stem cell transplantation are common therapeutic strategies for MM. Recently, proteasome inhibitors and immunomodulatory

Correspondence to: Dr Qicai Liu, Department of Joint Surgery, Zaozhuang Municipal Hospital, 41 Longtouzhong Road, Zaozhuang, Shandong 277101, P.R. China

E-mail: drqicailiu@outlook.com

Key words: Jumonji C domain-containing 2, $\beta$-catenin, multiple myeloma, cell viability drugs have also been used for MM therapy (5). However, the median survival rate for patients with MM is $\sim 50 \%$ (6). Furthermore, MM treatment leads to various adverse effects, including neutropenia, myelosuppression and thrombocytopenia $(7,8)$. Thus, understanding the factors involved in the progression of MM is of utmost importance for the development of novel therapies and for improving patient prognosis.

Epigenetic dysregulation plays an important role in the progression of MM (9). Abnormal methylation and the overproduction of misfolded proteins have been widely observed in MM tissues and cells $(10,11)$. For example, histone deacetylase (HDAC) inhibitors have become a focus of research in the treatment of MM (12). Panobinostat, an inhibitor of HDACs, exhibits cytotoxic activity against MM cells in combination with bortezomib in vitro and in vivo (13). HDAC3 can regulate the expression of DNA methyltransferase 1 (DNMT1) to trigger the proliferation of MM cells (14). Various micro (mi) RNAs and long non-coding (lnc)RNAs can also regulate the in vitro and in vivo progression of MM by targeting downstream signaling molecules (15).

Jumonji domain-containing proteins (JMJDs), which can recognize methylated histone as substrates, have attracted immense interest since previous findings showed their significant roles in the progression of a wide range of cancers $(16,17)$. JMJD2C, also known as KDM4C, can demethylate histone 3 lysine 9 trimethylation to relieve chromatin compaction by recruiting epigenetic writers and their readers, such as heterochromatin protein $1 \alpha$ and KRAB-associated protein 1 (18). JMJD2C can promote cell migration and invasion by modulating cullin-4A expression in lung cancer (19). It is required for the expression of interleukin-3 receptor subunit $\alpha$ and the survival of acute myeloid leukemia cells (20). However, the potential roles of JMJD, particularly those of JMJD2C, in the progression of MM have not yet been well defined.

The present study examined the expression of JMJD2 $\mathrm{A} / \mathrm{B} / \mathrm{C}$ in $\mathrm{MM}$ tissues and healthy controls. Furthermore, the potential effects of JMJD2C on the growth of MM cells were investigated. The results indicated that JMJD2C promoted the malignancy of MM via the activation of the $\beta$-catenin pathway.

\section{Materials and methods}

Patient sample collection. All patient and healthy control samples were collected at the Zaozhuang Municipal 
Hospital (Zaozhuang, China) between February 2017 and September 2018 following the approval of the Human Ethics Committee of Zaozhuang Municipal Hospital (approval no. ZZ-2018002). The patient group comprised 20 patients with newly-diagnosed MM (NDMM) who had not received any treatment and 20 healthy controls who had no history of basic or chronic diseases. The clinical characteristics of the participating patients and healthy controls are presented in Table I. All patients and healthy controls signed written informed consent forms in accordance with the Declaration of Helsinki. Mononuclear cells were separated from bone marrow by gradient density centrifugation, and plasma cells were then enriched from the bone marrow samples using CD138-coated magnetic beads (Miltenyi Biotech, Inc.) according to the manufacturer's instructions to ensure $>90 \%$ plasma cell purity. Subsequently, the mRNA expression of JMJD2 was examined by reverse transcription-quantitative polymerase chain reaction (RT-qPCR) assay.

Oncomine database and Kaplan-Meier plotter analysis. The online microarray database Oncomine ${ }^{\mathrm{TM}}$ was used to explore the mRNA expression levels of JMJD2C in MM and adjacent normal tissues (https://www.oncomine.org/resource/login. html). The conditions for filter setting were as follows: Gene, 'JMJD2C'; Cancer Type, 'Myeloma'. The studies incorporating mRNA expression data of $J M J D 2 C$ were obtained. Kaplan-Meier plotter (KM plotter, www.kmplot.com), which assesses the effect of 54,675 genes on survival using $>10,000$ cancer samples, was used to analyze survival data based on an online database (21). The time from beginning of surgery to death was defined as overall survival (OS). All patients were split into two groups according to the median level of the genes (high vs. low expression). The statistical analysis was carried out using a log-rank test. Kaplan-Meier survival plots were automatically generated.

$R N A$ extraction and $R T-q P C R$. Total RNA was separated using TRIzol ${ }^{\circledR}$ reagent (Invitrogen; Thermo Fisher Scientific, Inc.) in accordance with the manufacturer's instructions. The concentration and purity of the RNA were ascertained by UV spectrophotometry. Complementary DNA was synthesized using $1 \mu \mathrm{g}$ total RNA and the PrimeScript RT Reagent Kit with gDNA Eraser (Takara Bio, Inc.), according to the manufacturer's instructions. The mRNA expression of target genes was quantified using the SYBR-Green PCR kit (Takara Biotechnology Co., Ltd.) using an ABI 7500 Fast Real-Time PCR System (Applied Biosystems; Thermo Fisher Scientific, Inc.) with the primers listed in the primerbank (http://pga.mgh. harvard.edu/primerbank/). The following primers were used: JMJD2A forward, 5'-ATCCCAGTGCTAGGATAATGACC-3' and reverse, 5'-ACTCTTTTGGAGGAACAACCTTG-3'; JMJD2B forward, 5'-ACTTCAACAAATACGTGGCCTAC-3' and reverse, 5'-CGATGTCATCATACGTCTGCC-3'; JMJD2C forward, 5'-CGAGGTGGAAAGTCCTCTGAA-3' and reverse, 5'-GGGCTCCTTTAGACTCCATGTAT-3'; CTNNB1 (encodes $\beta$-catenin) forward, 5'-AAAGCGGCTGTTAGTCACTGG-3' and reverse, 5'-CGAGTCATTGCATACTGTCCAT-3'; casein kinase $1 \alpha(\mathrm{CK} 1 \alpha)$ forward, 5'-AGTGGCAGTGAAGCTAGAA TCT-3' and reverse, 5'-CGCCCAATACCCATTAGGAAGTT-3'; GSK3 $\beta$ forward, 5'-GGCAGCATGAAAGTTAGCAGA-3' and reverse, 5'-GGCGACCAGTTCTCCTGAATC-3'; GPADH forward, 5'-GGAGCGAGATCCCTCCAAAAT-3' and reverse, 5'-GGCTGTTGTCATACTTCTCATGG-3'; and pre-JMJD2C forward, 5'-AATTTGGCATCCAACCTGAG-3' and reverse, 5'-CATCTAACCCAGCCCACACT-3'. The PCR cycling conditions were $15 \mathrm{~min}$ at $95^{\circ} \mathrm{C}$, followed by 40 cycles for $10 \mathrm{sec}$ at $95^{\circ} \mathrm{C}, 30 \mathrm{sec}$ at $60^{\circ} \mathrm{C}$, and $1 \mathrm{sec}$ at $72^{\circ} \mathrm{C}$, and $1 \mathrm{cycle}$ of cooling for $30 \mathrm{sec}$ at $50^{\circ} \mathrm{C}$. The relative gene expression was calculated using the $2^{-\Delta \Delta \mathrm{Cq}}$ method (22). GAPDH was used as the internal reference for normalization.

Cell culture and transfection. Human U266 cells (established from the peripheral blood of a patient with an IgE myeloma) (23), RPMI8226 cells (derived from the peripheral blood of a 61-year-old male with MM) (24) and H929 cells (a human plasma cell myeloma culture having a rearranged cellular myc proto-oncogene) (25), which are all B cell maturation antigen-positive MM cell lines, were purchased from The Cell Bank of Type Culture Collection of The Chinese Academy of Sciences and maintained in the authors' laboratory. All cell lines were authorized by short tandem repeat genotyping. Cells were cultured in RPMI-1640 (Invitrogen; Thermo Fisher Scientific, Inc.) supplemented with $10 \%$ fetal bovine serum (FBS; Nichirei Biosciences, Inc.), $100 \mathrm{U} / \mathrm{ml}$ penicillin and $100 \mu \mathrm{g} / \mathrm{ml}$ streptomycin (Gibco; Thermo Fisher Scientific, Inc.) at $37^{\circ} \mathrm{C}$ in a $5 \% \mathrm{CO}_{2}$ humidified atmosphere. The vector control pcDNA3.1-NC was obtained from Chang Sha Axybio Bio-tech Co., Ltd. The cDNA of JMJD2C and GSK3 $\beta$ were amplified by general PCR and cloned into the expression vector pcDNA3.1 between the BamHI and EcoRI restriction sites using a Cold Fusion kit (System Biosciences, LLC). Small interfering (si)RNA targeting $\beta$-catenin (5'-CAC CUC CCA AGU CCU UUA U-3' and 5'-UUC UGC AGC UUC CUU GUC CUG-3') and a negative control (5'-UAG CGA CUA AAC ACA UCA A-3') were purchased from Shanghai GenePharma Co., Ltd. For transfection, cells were seeded at the density of $5 \times 10^{5}$ cells per well in 6 -well plates and cultured until the confluence reached $70-80 \%$. Next, cells were transfected with $20 \mu \mathrm{M}$ of each construct or siRNAs using Lipofectamine ${ }^{\circledR} 2000$ (Invitrogen; Thermo Fisher Scientific, Inc.) according to the manufacturer's instructions and maintained at $37^{\circ} \mathrm{C}$ for $6 \mathrm{~h}$. Then, medium was replaced with fresh DMEM containing 10\% FBS. After 24 h of transfection, cells were used for further experiments.

Inhibitor treatment. U266 cells were pre-transfected with vector control or JMJD2C construct for $12 \mathrm{~h}$ as described above, and further treated with inhibitors of NF- $\kappa \mathrm{B}[10 \mu \mathrm{M}$ BAY 11-7082 (BAY)], GSK3 $\beta / \beta$-catenin $(10 \mu \mathrm{M} \mathrm{LiCl}), \mathrm{PI} 3 \mathrm{~K} / \mathrm{Akt}$ [10 $\mu \mathrm{M}$ LY294002 (LY)], ERK1/2 [10 $\mu \mathrm{M}$ PD98059 (PD)] and EGFR [10 $\mu \mathrm{M}$ AG1478 (AG)] for $48 \mathrm{~h}$, and subsequently cell viability was determined

Cell viability assay. Cell viability was assessed with an MTT assay as described in previous studies $(26,27)$. Briefly, cells were seeded in 96 -well culture plates $\left(1 \times 10^{4}\right.$ cells/well) following pre-transfection with vector control or pcDNA/JMJD2C for $48 \mathrm{~h}$. Following incubation with MTT for $4 \mathrm{~h}$, the optical density of viable cells was measured at $450 \mathrm{~nm}$ using a SpectraMAX M5 spectrophotometer (Molecular Devices LLC). 
Table I. Clinical characteristics of the study cohorts.

\begin{tabular}{lccc}
\hline Parameter & HC & MM & Total \\
\hline $\mathrm{n}$ & 20 & 20 & 40 \\
Age, years & & & \\
$\quad$ Mean \pm SD & $47.9 \pm 9.4$ & $52.1 \pm 11.2$ & $50.1 \pm 10.5$ \\
Range & $33-71$ & $31-75$ & $31-75$ \\
Sex & & & \\
$\quad$ Male, n (\%) & $13(65 \%)$ & $12(60 \%)$ & $25(63 \%)$ \\
Female, n (\%) & $7(35 \%)$ & $8(40 \%)$ & $15(37 \%)$ \\
\hline
\end{tabular}

HC, healthy controls; MM, multiple myeloma.

Western blot analysis. Cells were lysed using radio-immunoprecipitation assay lysis buffer containing protease inhibitors (Beyotime Institute of Biotechnology). The proteins concentration was measured using a bicinchoninic acid protein assay kit (Beyotime Institute of Biotechnology). Proteins $(25 \mu \mathrm{g})$ were separated by SDS-PAGE on $12 \%$ gel, and then electrotransferred to polyvinylidene difluoride membranes (EMD Millipore). The membranes were blocked with 5\% (w/v) non-fat milk at room temperature for $2 \mathrm{~h}$, and incubated overnight at $4{ }^{\circ} \mathrm{C}$ with the following polyclonal primary antibodies (all from Abcam at a dilution of 1:1,000): Anti-JMJD2C (cat. no. ab226480), anti-proliferating cell nuclear antigen (PCNA; cat. no. ab18197), anti- $\beta$-catenin (cat. no. ab6302), anti-phosphorylated (p)- $\beta$-catenin (cat. no. ab81305), anti-H2A.X (cat. no. ab229914), anti-CK1 $\alpha$ (cat. no. ab206652) and anti-GSK3 $\beta$ (cat. no. ab32391). Subsequently, membranes were incubated with a HRP-conjugated secondary antibody (1:10,000; cat. no. ab7090; Abcam) for $2 \mathrm{~h}$ at room temperature. The enhanced chemiluminescence system (EMD Millipore) was used to identify the protein bands and visualized using a Gel imager camera (Bio-Rad Laboratories, Inc.). The subcellular localization of $\beta$-catenin was examined using the Nuclear and Cytoplasmic Protein Extraction kit (Beyotime Institute of Biotechnology) and western blot analysis. Semi-quantification was performed using ImageJ software (version 1.46; National Institutes of Health), and the signal of control was set to $100 \%$ for normalization. Results were obtained in uncalibrated units.

$m R N A$ and protein stability. In order to evaluate the effects of JMJD2C on the stability of $\beta$-catenin, cells were treated with $10 \mu \mathrm{g} / \mathrm{ml}$ ActD (Sigma-Aldrich; Merck KGaA), CHX (Sigma-Aldrich; Merck KGaA), or an equal volume of solvent (DMSO) as the control. The mRNA and protein expression of $\beta$-catenin was then examined by RT-qPCR and western blotting, respectively, according to the same methods outlined above. Relative expression levels were calculated to the levels of GAPDH.

Chromatin immunoprecipitation (ChIP) assay. The ChIP-PCR assay for the enrichment of $\beta$-catenin promoter in JMJD2C was performed as previously described (28) using a ChIP assay kit (cat. no. 17-10086; Sigma-Aldrich; Merck KGaA) according to the manufacturer's protocol. Briefly, cells were cultured to
90-100\% confluence. After washing three times with PBS, cells were cross-linked with $1 \%$ formaldehyde (Sigma-Aldrich; Merck KGaA), lysed with $2 \mathrm{ml}$ lysis buffer (50 mM Tris-HCl, $\mathrm{pH} 8.1 / 1 \% \mathrm{SDS} / 10 \mathrm{mM}$ EDTA protease inhibitors) at $4^{\circ} \mathrm{C}$, and sonicated $4 \times 15$ times at $4^{\circ} \mathrm{C}$. The chromatin fragments were incubated with $3 \mu \mathrm{g}$ affinity-purified antibodies against JMJD2C (cat. no. ab27532; Abcam) or IgG (cat. no. ab2410; Abcam) at $4{ }^{\circ} \mathrm{C}$ overnight and precipitated using protein $\mathrm{A} / \mathrm{G}$ beads (cat. no. sc-2002; Santa Cruz Biotechnology, Inc.) coupled to magna beads. The DNA fragments were extracted using phenol/chloroform and used as templates for PCR. As to PCR, $1 \mu \mathrm{l}$ from a $50 \mu \mathrm{l}$ DNA extraction and 38 cycles of amplification were used. The primer sequences for the CTNNB1 promoter was as follows: Forward, 5'-GTA GAG ACG GGG TTT CAC CA-3' and reverse, 5'-CCT GGG CAA TAA GAG CAA AA-3'. cycle quantification was determined for both immunoprecipitated DNA and known amount of DNA from input sample using the $2^{-\triangle \Delta C q}$ method (22). The products were confirmed by $3 \%$ agarose gel electrophoresis. Each experiment was performed in triplicate.

Promoter activity assay. The promoter activities of $\beta$-catenin were analyzed by dual-luciferase reporter assay according to the protocol of a previous study (29). Cells were co-transfected with pGL-CTNNB1, pRL-TK, vector control or JMJD2C construct for $24 \mathrm{~h}$, and then the promoter activity was measured using a dual-luciferase reporter assay. Briefly, the -1,000-bp PCR-generated promoter fragment of $\beta$-catenin was inserted into the pGL3-Basic vector (Promega Corporation). Cells $\left(5 \times 10^{3}\right.$ cells/well) seeded in 96 -well plate were transfected with a plasmid using Lipofectamine ${ }^{\circledR} 2000$ (Invitrogen; Thermo Fisher Scientific, Inc.). Luciferase activity was examined using the Dual Luciferase Reporter Assay System (Promega Corporation) according to the manufacturer's protocols. The firefly luciferase was normalized to a control reporter Renilla luciferase in the same sample.

Statistical analysis. Each experiment was performed in triplicate. Data are presented as the means \pm standard deviation, and were analyzed using GraphPad Prism 6.0 software (GraphPad Software, Inc.). Differences between groups were evaluated using a Student's t-test for two groups or one-way ANOVA followed by Bonferroni's post hoc test when making pairwise comparisons among $\geq 3$ groups of data. $\mathrm{P}<0.05$ was considered to indicate a statistically significant difference.

\section{Results}

$J M J D 2 C$ is upregulated in MM tissues. In order to evaluate the role of JMJD2 in the progression of MM, the mRNA expression levels of JMJD2A, JMJD2B and JMJD2C in the bone marrow samples of 20 healthy controls and 20 patients with MM were examined. The results revealed that compared with the healthy controls, JMJD2C expression was significantly upregulated in the samples from patients with MM, while the expression of JMJD2A or JMJD2B in the samples from patients with $\mathrm{MM}$ or healthy controls exhibited no significant difference (Fig. 1A-C). In addition, an association analysis between JMJD2C expression and the clinicopathological features of patients with MM was performed, and the results demonstrated that JMJD2C expression was not 
A

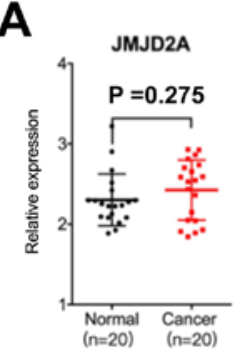

B

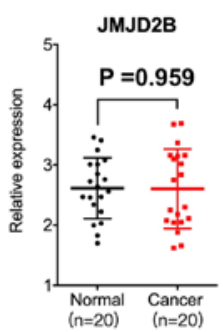

C

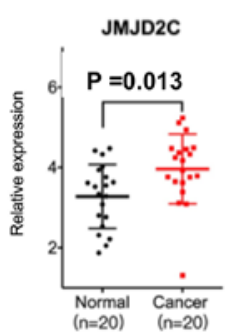

D

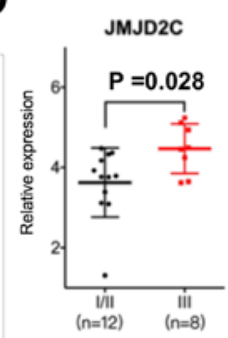

E

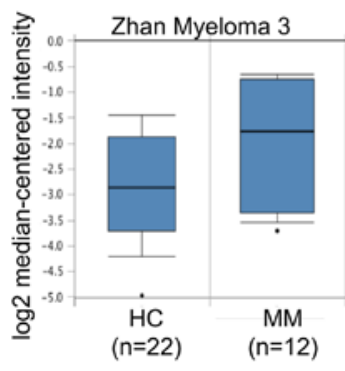

$F$

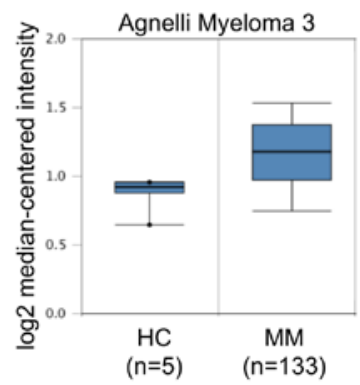

G

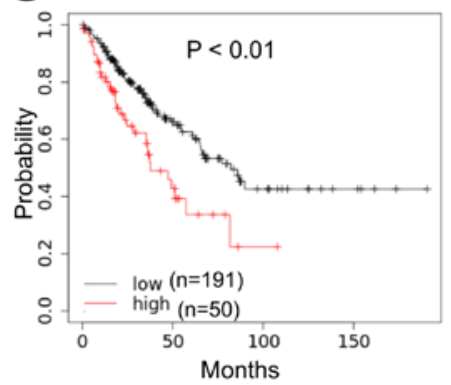

Figure 1. Expression of JMJD2 in MM tissues. Expression of (A) JMJD2A, (B) JMJD2B or (C) JMJD2C was detected by RT-qPCR in plasma of 20 patients with or without MM. (D) Expression of JMJD2C in patients with MM at different stages using the International Staging System. Expression of JMJD2C in human MM cancer tissues and normal mucosa tissues from (E) Zhan and (F) Agnelli using the Oncomine database. (G) OS in patients with MM with high $(n=50)$ vs. low ( $n=191)$ levels of JMJD2C plotted by the Kaplan-Meier method. Each data point represents fold-change for RT-qPCR. JMJD, Jumonji domain-containing protein; RT-qPCR, reverse transcription-quantitative PCR; MM, multiple myeloma; HC, healthy control.

A

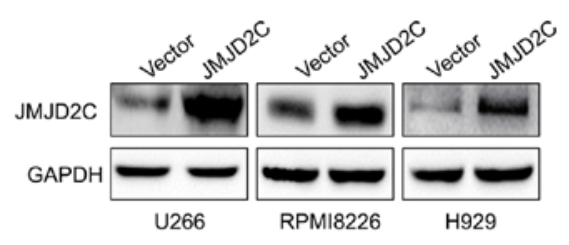

D

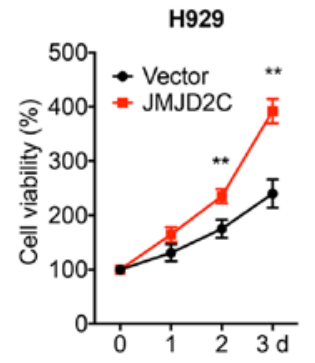

B
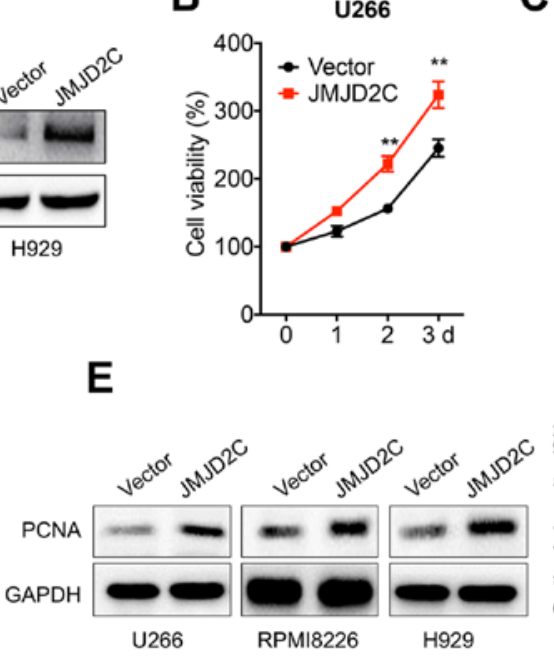

C
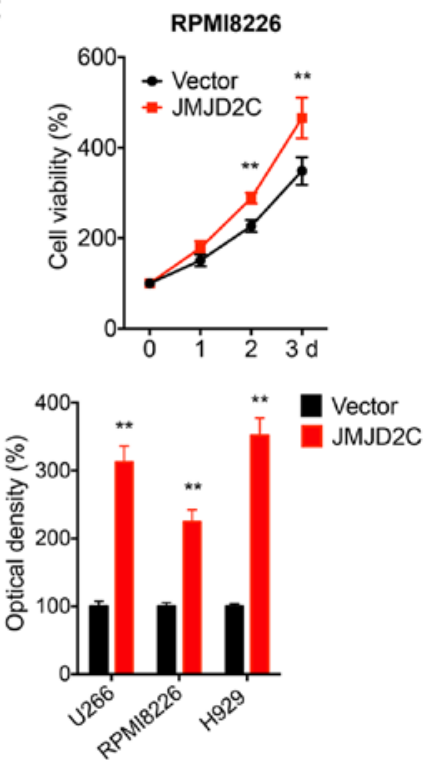

Figure 2. JMJD2C increases cell viability of multiple myeloma cells. (A) Cells were transfected with vector control (pcDNA) or pcDNA/JMJD2C for 24 h, and protein expression was measured. (B) U266, (C) RPMI8226 or (D) H929 cells were transfected with pcDNA or pcDNA/JMJD2C for the indicated time periods, and cell viability was determined. (E) Cells were transfected with pcDNA or pcDNA/JMJD2C for $24 \mathrm{~h}$, and then the expression of PCNA was detected. Data are presented as means $\pm \mathrm{SD}$ of three independent experiments. ${ }^{* *} \mathrm{P}<0.01$ vs. vector control. JMJD2C, Jumonji C domain-containing 2 ; PCNA, proliferating cell nuclear antigen.

related to sex, age or renal insufficiency in the patients with MM (data not shown). However, the patients with MM with higher international staging system (ISS) stages (30) had significantly higher levels of JMJD2C than those with lower ISS stages (Fig. 1D). The data from the Oncomine database revealed that the increased expression of JMJD2C in $\mathrm{MM}$ tissues compared with adjacent normal tissues on the basis of the data from Zhan (Fig. 1E) and Agnelli (Fig. 1F) on myeloma. Using the online bioinformatics tool
Kaplan-Meier plotter (31), it was found that patients with MM with increased expression of JMJD2C showed significantly reduced OS (Fig. 1G). All these data indicated that JMJD2C was upregulated in MM tissues.

JMJD2C increases cell viability of MM cells. In order to evaluate the potential roles of JMJD2C in the progression of MM, human MM U266, RPMI8226 and H929 cells were transfected with JMJD2C constructs (Fig. 2A). The data 
A

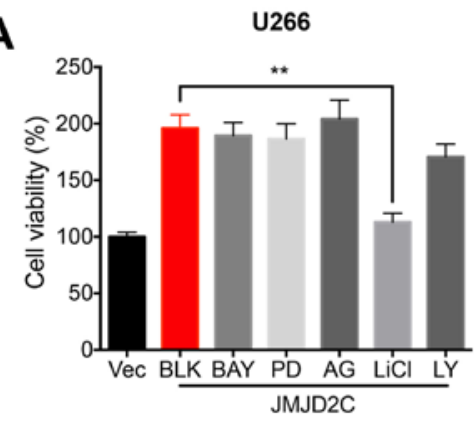

B

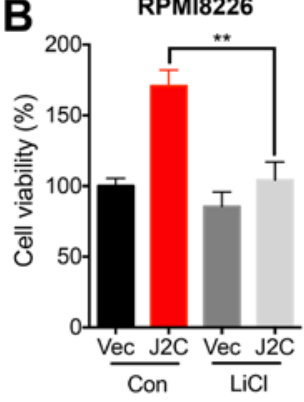

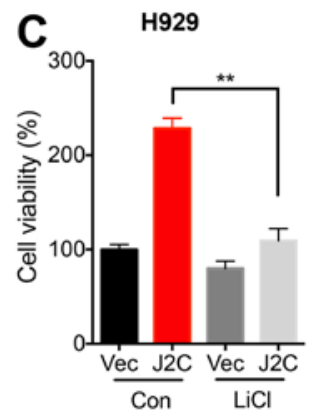

U266

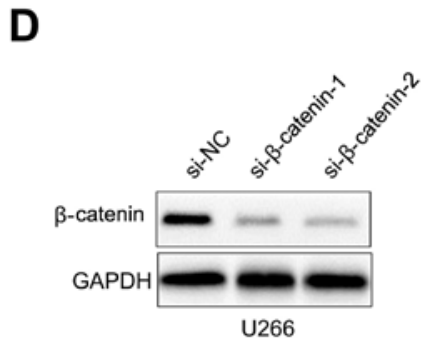

E
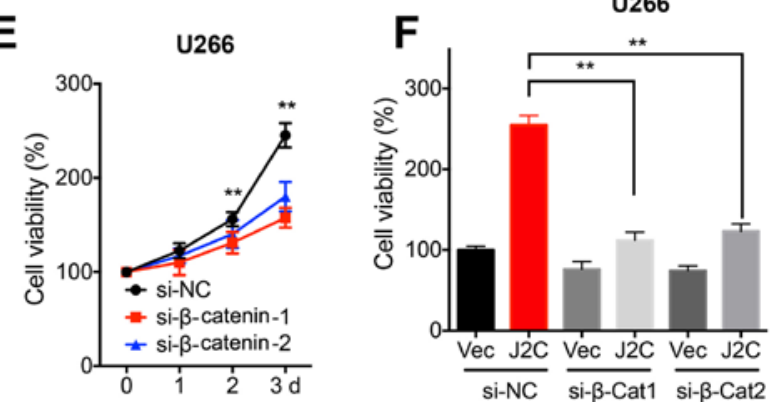

G

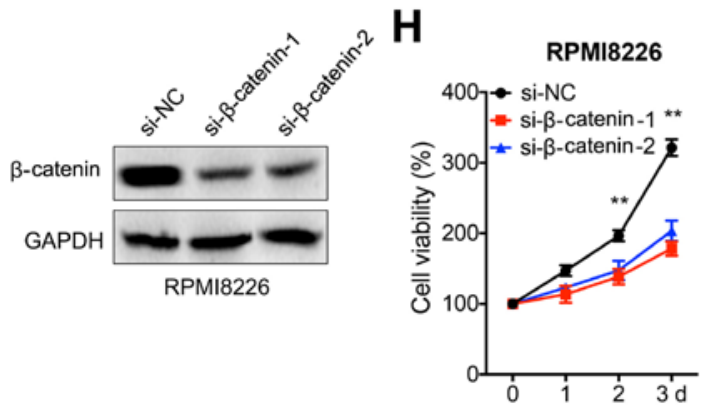

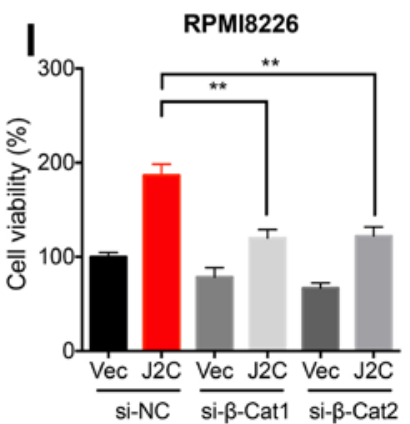

Figure 3. $\beta$-catenin signals are involved in JMJD2C-induced cell viability of multiple myeloma cells. (A) U266 cells were pre-transfected with vector control or JMJD2C construct for $12 \mathrm{~h}$ and further treated with inhibitors of NF-kB (10 $\mu \mathrm{M} \mathrm{BAY}), \mathrm{GSK} 3 \beta / \beta$-catenin $(10 \mu \mathrm{M} \mathrm{LiCl}), \mathrm{PI} 3 \mathrm{~K} / \mathrm{Akt}(10 \mu \mathrm{M} \mathrm{LY}), \mathrm{ERK} 1 / 2$ $(10 \mu \mathrm{M} \mathrm{PD})$ and EGFR $(10 \mu \mathrm{M} \mathrm{AG})$ for $48 \mathrm{~h}$, and subsequently cell viability was determined. (B) RPMI8226 or (C) H929 cells were pre-transfected with vector control or JMJD2C construct for $12 \mathrm{~h}$ and further treated with or without $10 \mu \mathrm{M} \mathrm{LiCl}$ for $48 \mathrm{~h}$, and subsequently cell viability was determined. (D) U266 cells were transfected with si-NC or si- $\beta$-catenin-1/-2 for $24 \mathrm{~h}$. (E) U266 cells were transfected with si-NC or si- $\beta$-catenin- $1 /-2$ for the indicated time periods, and cell viability was measured. (F) Cells were co-transfected with vector control, JMJD2C construct, si-NC or si- $\beta$-catenin-1/-2 for $48 \mathrm{~h}$, following which, cell viability was detected. (G) RPMI8226 cells were transfected with si-NC or si- $\beta$-catenin-1/-2 for $24 \mathrm{~h}$. (H) RPMI8226 cells were transfected with si-NC or si- $\beta$-catenin-1/-2 for the indicated time periods, and then cell viability was determined. (I) RPMI8226 cells were co-transfected with vector control, JMJD2C construct, si-NC or si- $\beta$-catenin- $1 /-2$ for $48 \mathrm{~h}$, and subsequently cell viability was measured. Data are presented as means \pm SD of three independent experiments. ${ }^{*} \mathrm{P}<0.01$ vs. si-NC or as indicated. JMJD2C, Jumonji C domain-containing 2; BAY, BAY 11-7082; LY, LY294002; PD, PD98059; AG, AG1478; si-, small interfering RNA; NC, negative control.

demonstrated that the overexpression of JMJD2C significantly increased the viability of U266 (Fig. 2B), RPMI8226 (Fig. 2C) and H929 (Fig. 2D) cells. In addition, the expression of proliferating cell nuclear antigen (PCNA), a proliferation marker, was significantly increased in MM cells transfected with JMJD2C (Fig. 2E). These results indicated that JMJD2C increased the malignancy of MM cells.

$\beta$-catenin signals are involved in the JMJD2C-induced growth of $M M$ cells. It has been reported that various signaling pathways, such as PI3K/Akt, ERK1/2, NF- $\kappa$ B, GSK3 $\beta / \beta$-catenin and EGFR can trigger the malignancy of MM (7). The present study found that $\mathrm{LiCl}$, an inhibitor of GSK3 $\beta$, abolished the JMJD2C-induced cell viability of U266 cells (Fig. 3A). The inhibitors of other pathways, such as PI3K/Akt, ERK1/2, $\mathrm{NF}-\kappa \mathrm{B}$ and EGFR, had no effect on JMJD2C-induced cell viability of U266 cells (Fig. 3A). Therefore, further assays focused on investigating the potential roles of GSK3 $\beta / \beta$-catenin in JMJD2C-regulated malignancy of MM cells. Furthermore, $\mathrm{LiCl}$ attenuated the JMJD2C-induced cell viability of RPMI8226 (Fig. 3B) and H929 (Fig. 3C) cells. In addition, the expression of $\beta$-catenin was knocked down in U266 cells using specific siRNA (Fig. 3D). The data demonstrated that the knockdown of $\beta$-catenin suppressed the viability of U266 cells (Fig. 3E) and attenuated the JMJD2C-induced cell viability of U266 cells (Fig. 3F). Consistently, the knockdown of $\beta$-catenin in RPMI8226 cells (Fig. 3G) also suppressed cell viability (Fig. 3H) and attenuated JMJD2C-induced cell viability (Fig. 3I).

JMJD2C increases the transcription of $\beta$-catenin in MM cells. The potential roles of JMJD2C in the expression and activation of $\beta$-catenin were further evaluated. The data demonstrated that the overexpression of JMJD2C increased 

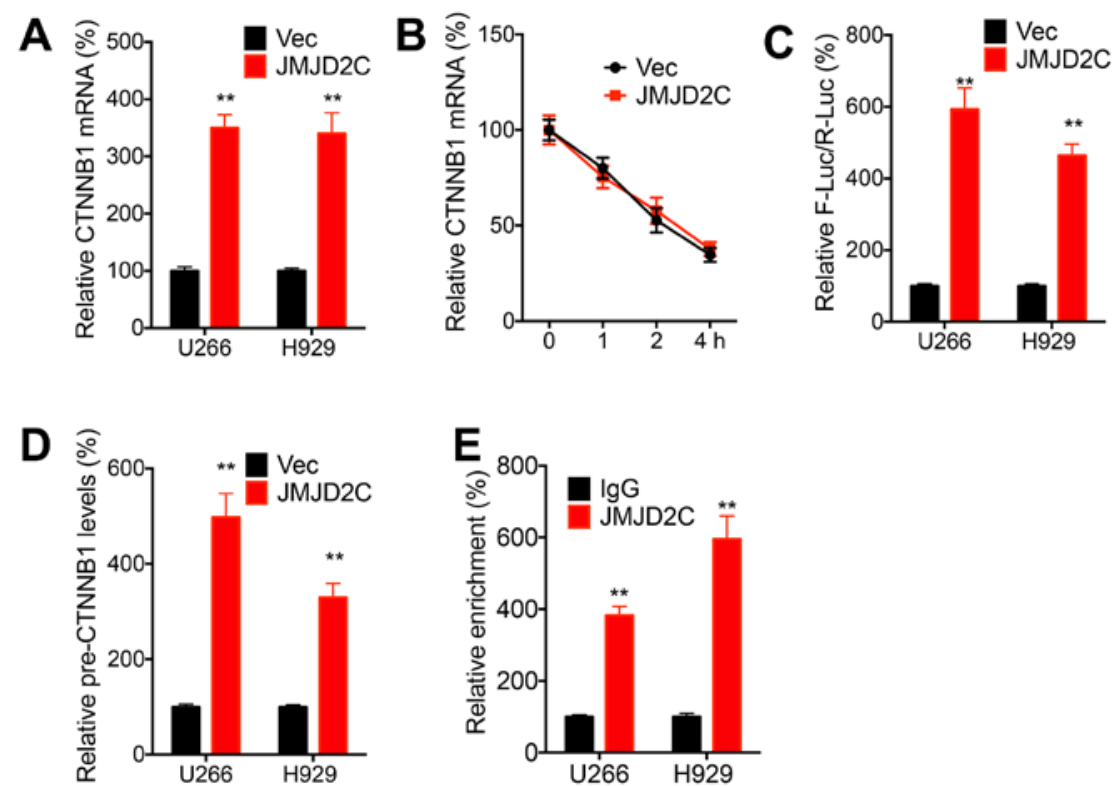

Figure 4. JMJD2C increases the transcription of $\beta$-catenin in multiple myeloma cells. (A) Cells were transfected with vector control or JMJD2C construct for $24 \mathrm{~h}$, the mRNA expression of CTNNB1 was determined. (B) U266 cells were pre-transfected with vector control or JMJD2C construct for $24 \mathrm{~h}$ and treated with ActD for the indicated time periods, following which, the mRNA expression of CTNNB1 was measured. (C) Cells were co-transfected with pGL-CTNNB1, pRL-TK, vector control or JMJD2C construct for $24 \mathrm{~h}$, and then the promoter activity was measured by dual-luciferase analysis. (D) Cells were transfected with vector control or JMJD2C construct for $24 \mathrm{~h}$, and subsequently the expression of precursor CTNNB1 mRNA was measured. (E) The relative enrichment of CTNNB1 promoter on JMJD2C was determined by chromatin immunoprecipitation-PCR. Data are presented as means \pm SD of three independent experiments. ${ }^{* *} \mathrm{P}<0.01$ vs. vector control. JMJD2C, Jumonji C domain-containing 2; CTNNB1, catenin $\beta-1$.

A

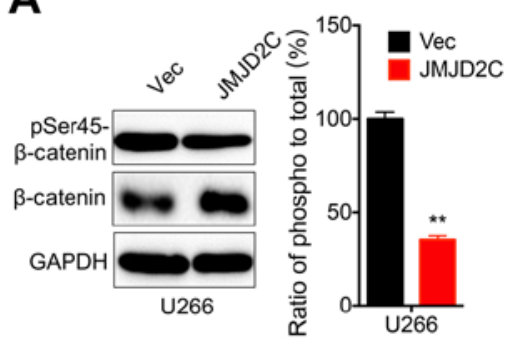

C

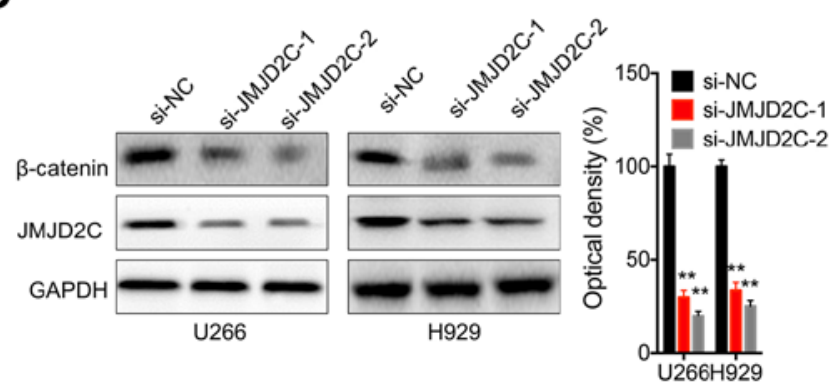

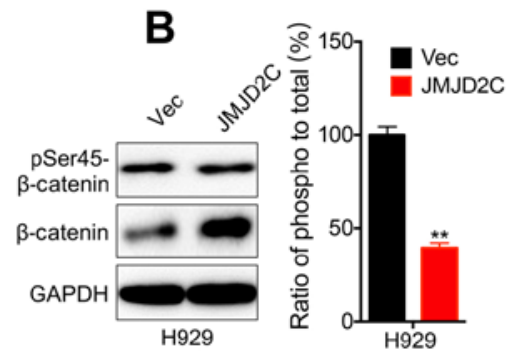

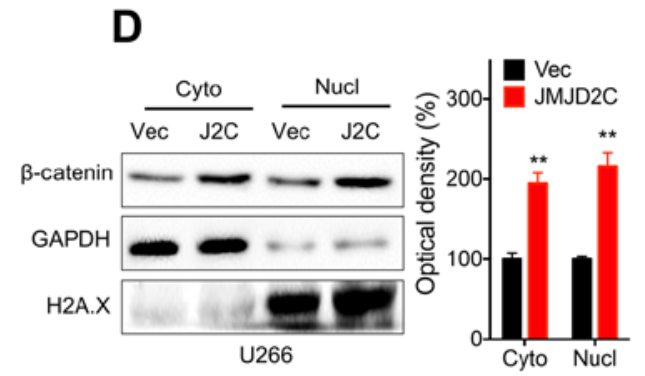

$\mathbf{E}$

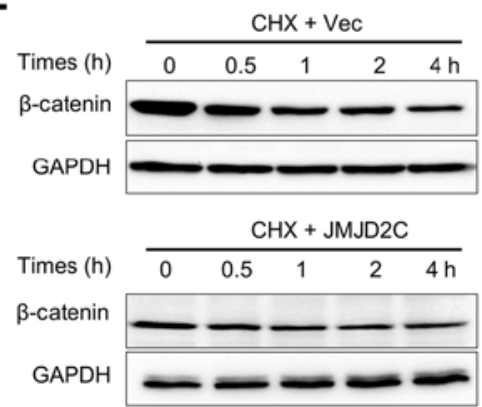

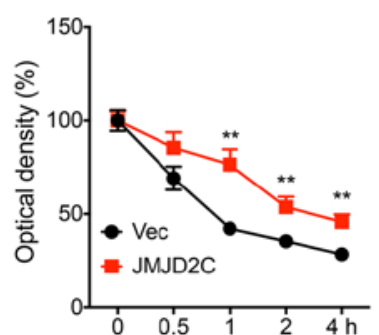

Figure 5. JMJD2C activates $\beta$-catenin in multiple myeloma cells. (A) U266 or (B) H929 cells were pre-transfected with vector control or JMJD2C construct for $24 \mathrm{~h}$, and then the phosphorylation and total expression of $\beta$-catenin was determined, and the relative phosphorylation levels of $\beta$-catenin were analyzed. (C) Proof of transfection for transfection with si-JMJD2C-1 and -2. (D) U266 cells were pre-transfected with vector control or JMJD2C construct for 24 h, following which, the subcellular localization of $\beta$-catenin was detected. (E) U266 cells were pre-transfected with vector control or JMJD2C construct for $24 \mathrm{~h}$ and then further treated with CHX for the indicated time periods, and then the expression of $\beta$-catenin was measured. Data are presented as means \pm SD of three independent experiments. ${ }^{* *} \mathrm{P}<0.01$ vs. vector control or si-NC. JMJD2C, Jumonji C domain-containing 2; p-, phosphorylated; si-, small interfering RNA; NC, negative control.

the mRNA expression of CTNNB1 in both the U266 and H929 cells (Fig. 4A). However, the overexpression of JMJD2C had no significant effect on the mRNA stability of CTNNB1 in U266 cells (Fig. 4B), which indicated that JMJD2C may regulate the transcription of CTNNB1 in MM cells. The luciferase reporter assay revealed that JMJD2C increased the promoter activities of CTNNB1 in both U266 and H929 cells (Fig. 4C). Consistently, the overexpression of JMJD2C 
A

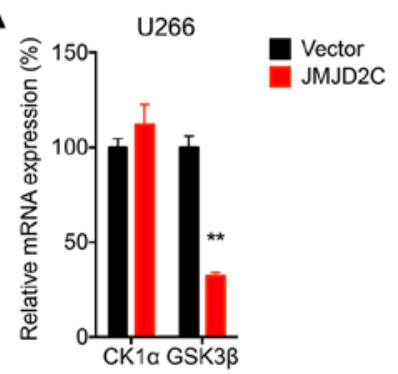

C

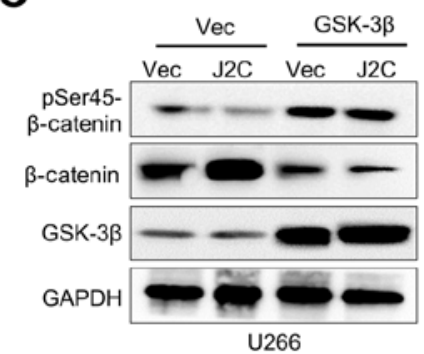

$\mathbf{F}$

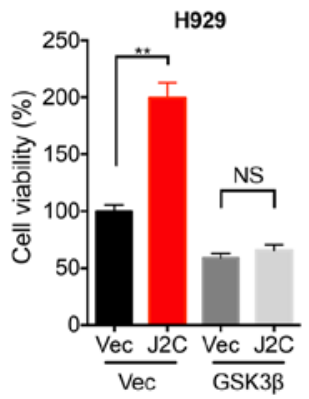

B
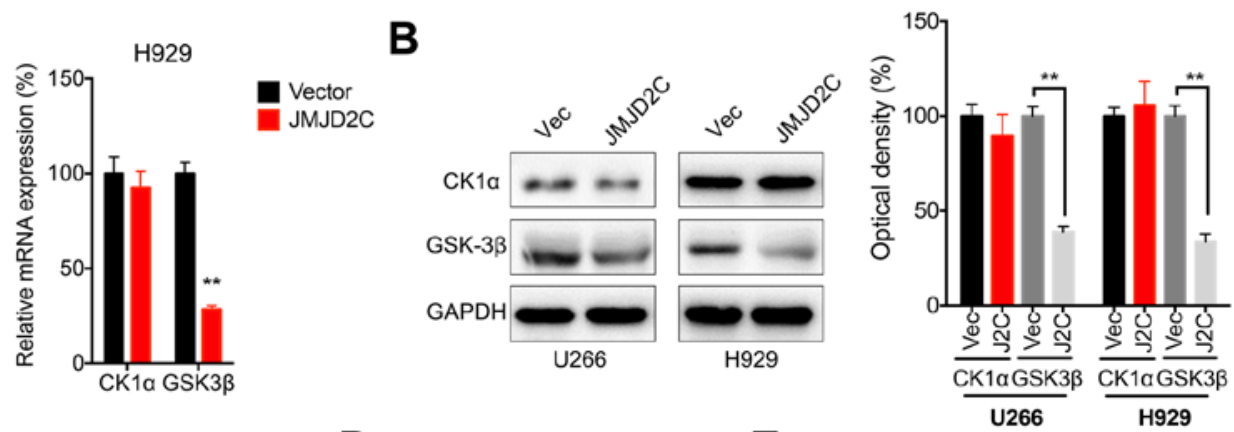

E
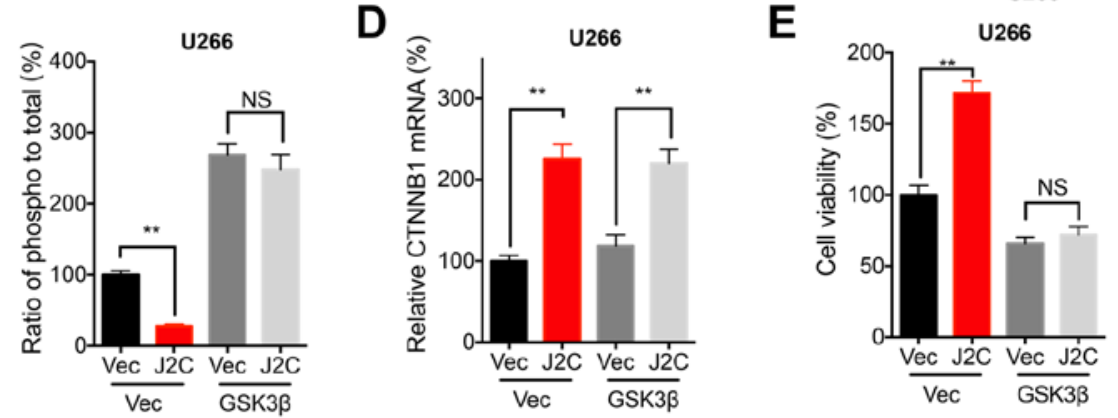

Figure 6. GSK3 $\beta$ is involved in JMJD2C-induced activation of $\beta$-catenin and malignancy of multiple myeloma cells. U266 or H929 cells were transfected with vector control or JMJD2C construct for $24 \mathrm{~h}$, and then the (A) mRNA and (B) protein expression of CK1 $\alpha$ and GSK3 $\beta$ were determined. U266 cells were co-transfected with vector control, pcDNA/JMJD2C and pcDNA/GSK3 $\beta$ alone or together for $24 \mathrm{~h}$, following which, the (C) phosphorylation and (D) mRNA of $\beta$-catenin were detected. (E) U266 or (F) H929 cells were co-transfected with vector control, pcDNA/JMJD2C and pcDNA/GSK3 $\beta$ alone or together for $48 \mathrm{~h}$, and subsequently cell viability was measured. Data are presented as means \pm SD of three independent experiments. ${ }^{* *} \mathrm{P}<0.01$ vs. vector control or as indicated. NS, not significant; JMJD2C, Jumonji C domain-containing 2; CK1 $\alpha$, casein kinase 1 $\alpha$; p-, phosphorylated; si-, small interfering RNA; NC, negative control.

increased the precursor mRNA expression of CTNNB1 in both U266 and H929 cells (Fig. 4D). ChIP-PCR revealed that the promoter of CTNNB1 was directly enriched with JMJD2C antibody (Fig. 4E). These results indicated that JMJD2C increased the transcription of $\beta$-catenin in MM cells.

$J M J D 2 C$ activates $\beta$-catenin in MM cells. Phosphorylation is critical for the activation and subcellular localization of $\beta$-catenin in human cells (32). In the present study, western blot analysis revealed that the overexpression of JMJD2C notably increased the expression of $\beta$-catenin in both U266 (Fig. 5A) and H929 (Fig. 5B) cells. The relative phosphorylation of $\beta$-catenin was significantly decreased in cells transfected with JMJD2C constructs (Fig. 5A and B). Consistently, the knockdown of JMJD2C significantly decreased the expression of $\beta$-catenin in both U266 and H929 cells (Fig. 5C). Furthermore, the overexpression of JMJD2C increased the nuclear localization of $\beta$-catenin in U266 cells (Fig. 5D). In addition, the overexpression of JMJD2C increased the protein stability of $\beta$-catenin in U266 cells (Fig. 5E). All these data indicated that
JMJD2C increased the expression and activation of $\beta$-catenin in $\mathrm{MM}$ cells.

GSK3 $\beta$ is involved in the JMJD2C-induced activation of $\beta$-catenin and malignancy of MM cells. CK1 $\alpha$ and GSK3 $\beta$ are crucial for the phosphorylation of $\beta$-catenin in cancer cells (33). The data of the present study demonstrated that JMJD2C overexpression significantly decreased the mRNA (Fig. 6A) and protein (Fig. 6B) expression of GSK3 $\beta$, but not that of CK1 $\alpha$, in both U266 and H929 cells. Furthermore, the overexpression of GSK3 $\beta$ attenuated the JMJD2C-induced decrease in the phosphorylation of $\beta$-catenin in U266 cells (Fig. 6C). However, the overexpression of GSK $3 \beta$ had no effect on the JMJD2C-induced mRNA expression of CTNNB1 (Fig. 6D). The cell viability assay revealed that the overexpression of GSK3 $\beta$ attenuated the JMJD2C-induced increase in the cell viability of U266 (Fig. 6E) and H929 (Fig. 6F) cells. All these results confirmed that GSK3 $\beta$ was involved in the JMJD2C-induced activation of $\beta$-catenin and the malignancy of MM cells. 


\section{Discussion}

The data of the present study demonstrated that JMJD2C was upregulated in MM tissues and promoted the malignancy of MM cells. As one of the most important histone demethylases, JMJD2C can play crucial roles in the progression of various types of cancer, such as breast (34), prostate (35) and lung (19) cancer. For example, the knockdown of JMJD2C has been reported to inhibit the proliferation of breast cancer cells in vitro and in vivo (36). In colorectal cancer cells, JMJD2C has been found to stimulate the proliferation of colon cancer cells by upregulating the levels of cyclin D1 and Fos-related antigen 1 (36). Consistently, the present study confirmed that the expression of JMJD2C was upregulated in MM tissues. The overexpression of JMJD2C increased the cell viability of MM cells. The present study confirmed the oncogenic roles of JMJD2C in the progression of MM.

The present study found that $\beta$-catenin was involved in the JMJD2C-induced malignancy of MM cells, which was evidenced by the finding that the targeted inhibition of $\beta$-catenin signals abolished the JMJD2C-induced cell viability of MM cells. As a highly conserved signal transduction pathway, $\beta$-catenin can regulate a wide range of cellular processes, including proliferation and the cell cycle (37). The hyperactivation of $\beta$-catenin signaling is considered one of the hallmarks of MM (38). Several previous studies revealed that the inhibition of $\beta$-catenin signals can suppress the progression of MM and may be potentially beneficial for patients with MM (39-41). The present study also demonstrated that the inhibition of $\beta$-catenin significantly suppressed the cell viability of MM cells.

The data of the present study indicated that JMJD2C increased the transcription and activation of $\beta$-catenin in MM cells, which was evidenced by the results that JMJD2C positively regulated its promoter activity and protein stability. Notably, $\beta$-catenin has been demonstrated to bind to the JMJD2C promoter to increase its transcription in colon cancer cells (42). It is suggested that there may be a positive feedback loop between JMJD2C and $\beta$-catenin in human cancer cells. Furthermore, lysine demethylase $5 \mathrm{~A}$ interacts with CCAAT/enhancer-binding protein $\beta$ and their interaction cooperatively inhibits Wnt6 transcription and the activation of the Wnt/ $\beta$-catenin pathway (43). The interaction between JMJDs and the $\beta$-catenin pathway warrants further investigations.

In conclusion, the present study demonstrated that JMJD2C promoted the malignancy of MM cells via the activation of $\beta$-catenin. Although the interaction between JMJDs and $\beta$-catenin requires further investigation, the data of the present study indicated that the targeted inhibition of JMJD2C may be a potential therapeutic approach for MM.

\section{Acknowledgements}

Not applicable.

\section{Funding}

No funding was received.

\section{Availability of data and materials}

The datasets used and/or analyzed during the current study are available from the corresponding author on reasonable request.

\section{Authors' contributions}

ML and QL conceived and designed the present study, and confirm the authenticity of all the raw data. ML was involved in acquisition of data and QL analyzed and interpreted the data. ML and QL wrote, reviewed and revised the manuscript. Both authors read and reviewed the final manuscript.

\section{Ethics approval and consent to participate}

Approval for the present study was received from the Human Ethics Committee of Zaozhuang Municipal Hospital (Zaozhuang, China). All patients and healthy controls signed written informed consent forms in accordance with the Declaration of Helsinki.

\section{Patient consent for publication}

Written informed consent for publication was obtained from all participants

\section{Competing interests}

The authors declare that they have no competing interests.

\section{References}

1. Moreau P, San Miguel J, Sonneveld P, Mateos MV, Zamagni E, Avet-Loiseau H, Hajek R, Dimopoulos MA, Ludwig H, Einsele H, et al; ESMO Guidelines Committee: Multiple myeloma: ESMO Clinical Practice Guidelines for diagnosis, treatment and follow-up. Ann Oncol 28 (Suppl_4): iv52-iv61, 2017.

2. Merz AMA, Merz M, Hillengass J, Holstein SA and McCarthy P: The evolving role of maintenance therapy following autologous stem cell transplantation in multiple myeloma. Expert Rev Anticancer Ther 19: 889-898, 2019.

3. Gandolfi S, Vekstein C, Laubach JP, O'Brien A, Masone K, Munshi NC, Anderson KC and Richardson PG: The evolving role of transplantation in multiple myeloma: The need for a heterogeneous approach to a heterogeneous disease. Clin Adv Hematol Oncol 16: 564-574, 2018.

4. Robiou du Pont S, Cleynen A, Fontan C, Attal M, Munshi N, Corre J and Avet-Loiseau H: Genomics of Multiple Myeloma. J Clin Oncol 35: 963-967, 2017.

5. Chim CS, Kumar SK, Orlowski RZ, Cook G, Richardson PG, Gertz MA, Giralt S, Mateos MV, Leleu X and Anderson KC: Correction: Management of relapsed and refractory multiple myeloma: novel agents, antibodies, immunotherapies and beyond. Leukemia 33: 1058-1059, 2019.

6. Brioli A, Klaus M, Sayer H, Scholl S, Ernst T, Hilgendorf I, Scherag A, Yomade O, Schilling K, Hochhaus A, et al: The risk of infections in multiple myeloma before and after the advent of novel agents: A 12-year survey. Ann Hematol 98: 713-722, 2019.

7. Marino S, Petrusca DN and Roodman GD: Therapeutic targets in myeloma bone disease. Br J Pharmacol: Oct 24, 2019 (Epub ahead of print). doi: 10.1111/bph.14889.

8. Webb SL and Edwards CM: Novel therapeutic targets in myeloma bone disease. Br J Pharmacol 171: 3765-3776, 2014.

9. Barwick BG, Gupta VA, Vertino PM and Boise LH: Cell of Origin and Genetic Alterations in the Pathogenesis of Multiple Myeloma. Front Immunol 10: 1121, 2019.

10. Moreau P, Attal M and Facon T: Frontline therapy of multiple myeloma. Blood 125: 3076-3084, 2015. 
11. Yaqub S, Ballester $\mathrm{G}$ and Ballester O: Frontline therapy for multiple myeloma: A concise review of the evidence based on randomized clinical trials. Cancer Invest 31: 529-537, 2013.

12. Greig SL: Panobinostat: A Review in Relapsed or Refractory Multiple Myeloma. Target Oncol 11: 107-114, 2016.

13. Hideshima T, Richardson PG and Anderson KC: Mechanism of action of proteasome inhibitors and deacetylase inhibitors and the biological basis of synergy in multiple myeloma. Mol Cancer Ther 10: 2034-2042, 2011.

14. Harada T, Ohguchi H, Grondin Y, Kikuchi S, Sagawa M, Tai YT, Mazitschek R, Hideshima T and Anderson KC: HDAC3 regulates DNMT1 expression in multiple myeloma: Therapeutic implications. Leukemia 31: 2670-2677, 2017.

15. Pourhanifeh MH, Mahjoubin-Tehran M, Shafiee A Hajighadimi S, Moradizarmehri S, Mirzaei $\mathrm{H}$ and Asemi Z: MicroRNAs and exosomes: Small molecules with big actions in multiple myeloma pathogenesis. IUBMB Life 72: 314-333, 2020.

16. Van Rechem $C$ and Whetstine JR: Examining the impact of gene variants on histone lysine methylation. Biochim Biophys Acta 1839: 1463-1476, 2014.

17. Zhang X, Liu L, Yuan X, Wei Y and Wei X: JMJD3 in the regulation of human diseases. Protein Cell 10: 864-882, 2019.

18. Ayrapetov MK, Gursoy-Yuzugullu O, Xu C, Xu Y and Price BD: DNA double-strand breaks promote methylation of histone $\mathrm{H} 3$ on lysine 9 and transient formation of repressive chromatin. Proc Natl Acad Sci USA 111: 9169-9174, 2014.

19. Li N and Jiang D: Jumonji domain containing 2C promotes cell migration and invasion through modulating CUL4A expression in lung cancer. Biomed Pharmacother 89: 305-315, 2017.

20. Agger K, Miyagi S, Pedersen MT, Kooistra SM, Johansen JV and Helin K: Jmjd2/Kdm4 demethylases are required for expression of Il3ra and survival of acute myeloid leukemia cells. Genes Dev 30: 1278-1288, 2016.

21. Györffy B, Lanczky A, Eklund AC, Denkert C, Budczies J, Li Q and Szallasi Z: An online survival analysis tool to rapidly assess the effect of 22,277 genes on breast cancer prognosis using microarray data of 1,809 patients. Breast Cancer Res Treat 123 725-731, 2010

22. Livak KJ and Schmittgen TD: Analysis of relative gene expression data using real-time quantitative PCR and the 2(-Delta Delta C(T)) Method. Methods 25: 402-408, 2001

23. Nilsson K, Bennich H, Johansson SG and Pontén J: Established immunoglobulin producing myeloma (IgE) and lymphoblastoid (IgG) cell lines from an IgE myeloma patient. Clin Exp Immunol 7: 477-489, 1970.

24. Pellat-Deceunynk C, Amiot M, Bataille R, van Riet I, van Camp B, Omede P and Boccadoro M: Human myeloma cell lines as a tool for studying the biology of multiple myeloma: A reappraisal 18 years after. Blood 86: 4001, 1995. Published Erratum Blood 131: 154, 2018

25. Gazdar AF, Oie HK, Kirsch IR and Hollis GF: Establishment and characterization of a human plasma cell myeloma culture having a rearranged cellular myc proto-oncogene. Blood 67 $1542-1549,1986$

26. Kanasugi J, Hanamura I, Ota A, Karnan S, Lam VQ, Mizuno S, Wahiduzzaman M, Rahman ML, Hyodo T, Konishi H, et al: Biallelic loss of FAM46C triggers tumor growth with concomitant activation of Akt signaling in multiple myeloma cells. Cancer Sci 111: $1663-1675,2020$

27. Wahiduzzaman M, Ota A, Karnan S, Hanamura I, Mizuno S, Kanasugi J, Rahman ML, Hyodo T, Konishi H, Tsuzuki S, et al: Novel combined Ato- $\mathrm{C}$ treatment synergistically suppresses proliferation of Bcr-Abl-positive leukemic cells in vitro and in vivo. Cancer Lett 433: 117-130, 2018.
28. Soriano AA, de Cristofaro T, Di Palma T, Dotolo S, Gokulnath P, Izzo A, Calì G, Facchiano A and Zannini M: PAX8 expression in high-grade serous ovarian cancer positively regulates attachment to ECM via Integrin $\beta 3$. Cancer Cell Int 19: 303, 2019.

29. Hui RC, Francis RE, Guest SK, Costa JR, Gomes AR, Myatt SS, Brosens JJ and Lam EW: Doxorubicin activates FOXO3a to induce the expression of multidrug resistance gene ABCB1 (MDR1) in K562 leukemic cells. Mol Cancer Ther 7: 670-678, 2008.

30. Palumbo A, Avet-Loiseau H, Oliva S, Lokhorst HM, Goldschmidt H, Rosinol L, Richardson P, Caltagirone S, Lahuerta JJ, Facon T, et al: Revised International Staging System for Multiple Myeloma: A Report From International Myeloma Working Group. J Clin Oncol 33: 2863-2869, 2015.

31. Szász AM, Lánczky A, Nagy Á, Förster S, Hark K, Green JE, Boussioutas A, Busuttil R, Szabó A and Győrffy B: Cross-validation of survival associated biomarkers in gastric cancer using transcriptomic data of 1,065 patients. Oncotarget 7: 49322-49333, 2016.

32. Abdel-Magid AF: Wnt/ $\beta$-Catenin Signaling Pathway Inhibitors: A Promising Cancer Therapy. ACS Med Chem Lett 5: 956-957, 2014

33. Daugherty RL and Gottardi CJ: Phospho-regulation of Beta-catenin adhesion and signaling functions. Physiology (Bethesda) 22: 303-309, 2007.

34. Liu G, Bollig-Fischer A, Kreike B, van de Vijver MJ, Abrams J, Ethier SP an.d Yang ZQ: Genomic amplification and oncogenic properties of the GASC1 histone demethylase gene in breast cancer. Oncogene 28: 4491-4500, 2009.

35. Kahl P, Gullotti L, Heukamp LC, Wolf S, Friedrichs N, Vorreuther R, Solleder G, Bastian PJ, Ellinger J, Metzger E, et al: Androgen receptor coactivators lysine-specific histone demethylase 1 and four and a half LIM domain protein 2 predict risk of prostate cancer recurrence. Cancer Res 66: 11341-11347, 2006.

36. Ye Q, Holowatyj A, Wu J, Liu H, Zhang L, Suzuki T and Yang ZQ: Genetic alterations of KDM4 subfamily and therapeutic effect of novel demethylase inhibitor in breast cancer. Am J Cancer Res 5: 1519-1530, 2015.

37. Nusse R and Clevers H: Wnt/ $\beta$-Catenin Signaling, Disease, and Emerging Therapeutic Modalities. Cell 169: 985-999, 2017.

38. van Andel H, Kocemba KA, Spaargaren M and Pals ST: Aberrant Wnt signaling in multiple myeloma: Molecular mechanisms and targeting options. Leukemia 33: 1063-1075, 2019.

39. Wang H, Gong Y, Liang L, Xiao L, Yi H, Ye M, Roy M, Xia J, Zhou W, Yang C, et al: Lycorine targets multiple myeloma stem cell-like cells by inhibition of Wnt/ $\beta$-catenin pathway. $\mathrm{Br} \mathrm{J}$ Haematol 189: 1151-1164, 2020.

40. Su N, Wang P and Li Y: Role of Wnt/ $\beta$-catenin pathway in inducing autophagy and apoptosis in multiple myeloma cells. Oncol Lett 12: 4623-4629, 2016.

41. Schmeel LC, Schmeel FC, Kim Y, Endo T, Lu D and Schmidt-Wolf IG: Targeting the Wnt/beta-catenin pathway in multiple myeloma. Anticancer Res 33: 4719-4726, 2013.

42. Yamamoto $S$, Tateishi $K$, Kudo $Y$, Yamamoto $K$, Isagawa $T$, Nagae G, Nakatsuka T, Asaoka Y, Ijichi H, Hirata Y, et al: Histone demethylase KDM4C regulates sphere formation by mediating the cross talk between Wnt and Notch pathways in colonic cancer cells. Carcinogenesis 34: 2380-2388, 2013.

43. Guo L, Guo YY, Li BY, Peng WQ and Tang QQ: Histone demethylase KDM5A is transactivated by the transcription factor $\mathrm{C} / \mathrm{EBP} \beta$ and promotes preadipocyte differentiation by inhibiting Wnt/ $\beta$-catenin signaling. J Biol Chem 294: 9642-9654, 2019.

This work is licensed under a Creative Commons Attribution-NonCommercial-NoDerivatives 4.0 International (CC BY-NC-ND 4.0) License. 